\title{
THE EFFECT OF COGNITIVE BEHAVIORAL COUPLE THERAPY ON REDUCTION OF MARITAL CONFLICTS AND BURNOUT OF COUPLES
}

\author{
Amir Ali Rajani \\ BA in Psychology, Islamic Azad University, Gorgan Branch \\ Dr. Leyla Sadat Azizi \\ Faculty Member of Islamic Azad University (Central Tehran \& Gorgan Branches) \\ Samin Naeemi \\ BA in Psychology, Islamic Azad University, Gorgan Branch \\ Ali Asghar Amiri \\ BA in Psychology, Islamic Azad University, Gorgan Branch \\ Mohammad Javidan \\ BA in Psychology, Islamic Azad University, Gorgan Branch \\ Halime Darvishi Gholi Abad \\ BA in Psychology, Islamic Azad University, Gorgan Branch \\ Kiana Hosseini \\ BA in Psychology, Islamic Azad University, Gorgan Branch
}

\begin{abstract}
Introduction and objective: family is the most important institute of every society and the society will be developed if the family positively does their performances. If there is a conflict in the family, its performance will be disordered. This study has been conducted to assess the effect of cognitive behavioral couple therapy on reduction of marital conflicts and burnout of couples.

Methodology: the type of this experimental study is pretest-posttest with control and test groups. Statistical population of study includes couples of Golestan province, Iran. The sample size was obtained to 64 members using simple random sampling and they were placed into two test and control groups. Both groups were pretest before implementation of protocol and posttest was conducted for both groups after implementation of protocol. The obtained data were analyzed through SPSS20 software using formulas of mean and standard deviation as well as covariance formula at inferential level.

Findings: the analyses indicated that training of cognitive behavioral skills has a significant effect with coefficient of $0 / 46$ on marital conflicts and training of cognitive behavioral skills has a significant effect on marital burnout with coefficient of $0 / 65$.

Discussion and conclusion: according to the findings of this study, it is suggested to experts and consultants in field of family and family therapy consider training of cognitive behavioral skills as an important factor before marriage or within conflict between couples.
\end{abstract}

Keywords: cognitive behavioral couple therapy, marital conflicts, marital burnout

\section{INTRODUCTION}

Family is a vital and primitive social institute guaranteeing health of people as well as survival of society. All of societies should have a system to replace its members in order to be remained. Family would prepare possibility to realize this replacement (Fernans, 2006, quoted by Alimardani, 2011). Marriage is one of the most important needs affecting all aspects of human life for about half a century 
(Bastani, Golzari \& Roshani, 2011). The history of marriage goes back to the start of history love, kindness, marriage and marital conflicts have been always existed from the beginning of the creation. In fact, mental health of human is strongly related to a successful marriage (Mahmoodi et al, 2015).

Marriage would begin with a hope, hope to understand our feelings and accept us, and hope to gain sense of belonging, to be supported through a security (Davarnia, Zahrakar, Moayeri \& Shakarami, 2005). Most of the people hope to have an eternal love when they fall in love. This hope is so powerful that can affect healthy mind, make reasons meaningless and make eyes blind toward reality. After a while when couples face realities of life and daily problems, would understand the reality. In this case, couples might experience marital burnout and conflicts (Dentone, Veberton\& Golden, 2012).

Marital conflict has been defined as the high level of interactions along with hostile and stressful disagreement between couples as well as disrespect and misbehave (Robila\&Kerishenakamore, 2005). Conflict can effect on mental, physical and family health and many of studies have confirmed the relationship between marital conflicts and depression, eating disorders and specific disease such as cancer (Elinamane, 2004). Burnout is also a bad physical, mental, and emotional situation that effects on life of people who expect love to make a perfect life for them. Burnout occurs when couples find that their relationship has no significant effect on their life despite their efforts (Sadeghi, Zareefar \& Adeli, 2013).

Kayser believes that marital burnout is gradual reduction of emotional attachment to spouse along with alienation, apathy and indifference sense between couples and replacement of positive feelings with negative feelings. Pinese et al (2011) know burnout as a physical, mental and emotional fatigue that is created within long-term conflicts and emotional gaps. Since marital burnout includes decreased love, passion and increased hostile behaviors, it can lead to marital dissatisfaction and destruction of family foundation (Hosten, 2009). There are different approaches of family therapy and couple therapy with the aim of reducing conflicts and relationship confusion between couples. The purpose of couple therapy is to help couples to have appropriate adaptation with problems and learn effective methods in relationships (Rostami, 2014).

One of the psychological approaches is cognitive-behavioral approach to treat marital conflicts and marital burnout (Datilluo, 2005). The main factor in cognitive-behavioral approach is concentration on thoughts and feelings beside their effects on emotions and behavior (Yoneg et al, 2003). The cognitive behavioral pattern emphasizes on emotional and behavioral responses toward life events that are related to relevant interpretations to their thinking methods. These interpretations might be distorted or inappropriate (Backome et al, 2010). Family therapy is an intervention to change interactions between family members through improvement of family performance as a unit that is formed from members. Family therapist aims to break all patterns that make family members upset or destroy interpersonal relationships. Cognitive-behavioral approach toward family therapy assumes that family members can be influenced by each other or effect on each other (Dattilio, F. M., 2001). Therefore, behavior of a member of family would lead to behaviors, emotions and cognitions as response by other family members. In this regard, instability within family activities might lead to increase in vulnerability of family members against conflicts and creation of negative interactions (Simos, 2002).

According to the mentioned points, a healthy family is an ideal and reality and many studies that support the relationship between marriage and psychological health (Stutzer, \& Bruno, 2006). Married people have more life satisfaction and happiness beside mental and physical health, high self-esteem, and sense of mastery compared to single people (Durden, 2006). It would be essential to study effective factors in this field since sometimes there are conflicts and burnout between couples beside some harms such as divorce. Hence, the main issue of this study is to assess the effect of cognitive behavioral therapy on marital conflicts and burnout.

\section{METHODOLOGY}

The type of this experimental study is pretest-posttest with control and test groups. Statistical population of study includes couples of Golestan Province, Iran in 2015. 64 members were chosen as 
sample size through simple random sampling method and then they were placed into two test and control groups. The criteria for entering to study was having more than 5-years married life and criteria for exclusion from study was divorce experience. Both groups were pretested before implementation of protocol and then posttest was conducted for groups after implementation of protocol. The obtained data were analyzed using formulas of mean, and standard deviation as well as covariance formula as inferential level through SPSS20 software.

\section{MEASUREMENT TOOL}

\section{QUESTIONNAIRE OF COUPLE BURNOUT MEASUREMENT (1996)}

The scale of marital burnout is a self-evaluation tool has been designed to measure marital burnout level among couples. Couple burnout measurement (CBM) has been adopted from another self-evaluation tool that is applied to measure burnout. CBM was established by Pines (1996) (Pines \& Nunes, 2003; Laes \& Laes, 2001). This questionnaire includes 21 items that are divided into two main parts including physical fatigue and mental fatigue such as sense of worthlessness, frustration and anger to wife and all of these items are responded through a 7-scored scale. The level 1 includes lack of experience about the mentioned term and level 7 indicates the high experience about the considered term. It will take 15-20 minutes to complete the CBM (Pines, 1996, Shadab Trans, 2007). Evaluation of validity coefficient indicates that this coefficient has an internal inconsistency with variables within domain of $0 / 84$ and 0/90 (Pines \& Nunes, 2003; Laes, 2001). Navidi (2005) measured Cronbach's alpha of this questionnaire about 240 samples including 1200 nurses and 120 teacher in Iran and reported this coefficient equal to 0/86 (Davarnia et al, 2015).

\section{MARITAL CONFLICTS QUESTIONNAIRE (MCQ)}

Marital conflicts questionnaire (Sanaee, Alaghband, Falahati \& Hooman, 2008) has been established to assess marital conflicts. This questionnaire evaluates 8 dimensions of marital conflicts including reduced cooperation, reduced sexual relationship, increased emotional reactions, increased children support, increased personal relationships with relatives, reduced relationships with relatives of spouse and friends, separated financial affairs, and reduced effective relationship. This questionnaire is a tool with 54 questions that minimum and maximum of scores are calculated between 54 and 270 that maximum score of each subscale is equal to number of questions of that subscale multiplied by 5 . The items of this questionnaire are ranked within a 5-points LIKRET scale (always=5, mostly= 4sometimes $=3$, rarely $=2,1=$ never) and some items are reversely scored. The more the score is in this scale, the more the conflict is and the less the score, the less conflict and the better relationship is between couples.

To assess validity and reliability, the mentioned questionnaire was implemented for a 120 -members group with 48 men and 72 women who had referred to consultation center and for a control groups with 150 members including ordinary couples (68 men and 82 women). Cronbach's alpha was obtained to 0/96 for the whole questionnaire for a 270 -members group while this coefficient was obtained for 8 subscales as follows: reduced cooperation (0/81), reduced sexual relationship (0/61), increased emotional reactions $(0 / 70)$, increased children support $(0 / 33)$, increased personal relationships with relatives $(0 / 86)$, reduced relationships with relatives of spouse and friends $(0 / 89)$, separated financial affairs $(0 / 71)$, and reduced effective relationship (0/69).

\section{IMPLEMENTATION METHOD}

When the couples informed about the general goal and scope of study, they declared their conscious satisfaction about participation in study. The number of sessions (12 sessions) was determined at the first session, every session was 70 minutes and the time of next session was determined at the end of each session.

Summary of the content of cognitive behavioral sessions

\begin{tabular}{|c|c|c|}
\hline Row & \multicolumn{1}{|c|}{ Session name } & $\begin{array}{c}\text { Summarized description of } \\
\text { content of session }\end{array}$ \\
\hline First session & Familiarity and implementation & Questionnaires were \\
\hline
\end{tabular}




\begin{tabular}{|c|c|c|}
\hline & of pretest & $\begin{array}{l}\text { implemented for pretest in this } \\
\text { session after familiarity with } \\
\text { researcher }\end{array}$ \\
\hline Second session & $\begin{array}{l}\text { The first interventional } \\
\text { relationship }\end{array}$ & $\begin{array}{l}\text { Family members introduced } \\
\text { themselves in this session and } \\
\text { expressed their problems. At the } \\
\text { end of session, therapist assessed } \\
\text { and ranked the problems through } \\
\text { family involvement }\end{array}$ \\
\hline Third session & $\begin{array}{c}\text { Training of cognitive behavioral } \\
\text { skills }\end{array}$ & $\begin{array}{l}\text { Therapist taught family } \\
\text { members to resolve the problem } \\
\text { in this session so that family } \\
\text { members could benefit from } \\
\text { their abilities to effectively deal } \\
\text { with life problems }\end{array}$ \\
\hline Fourth session & Training of interpersonal skills & $\begin{array}{l}\text { In this session, therapist taught } \\
\text { consistent interpersonal skills to } \\
\text { family members and they } \\
\text { learned how to behave against } \\
\text { stressful personal situations }\end{array}$ \\
\hline Fifth session & $\begin{array}{l}\text { Training of skills to face stress } \\
\text { and detente }\end{array}$ & $\begin{array}{l}\text { Family members learned how to } \\
\text { deal with stress in this session } \\
\text { through proper behavior against } \\
\text { stressful situations/ therapist } \\
\text { taught detente to family } \\
\text { members et the second part of } \\
\text { this session }\end{array}$ \\
\hline Sixth session & Assertiveness training & $\begin{array}{l}\text { Therapist taught assertiveness to } \\
\text { family members in this session } \\
\text { this training included three } \\
\text { aspects: 1- assertiveness in } \\
\text { expression 2- assertive rejection } \\
\text { of improper demand 3- } \\
\text { assertiveness in behavior and } \\
\text { then inappropriate methods of } \\
\text { assertiveness was taught. }\end{array}$ \\
\hline Seventh session & Training of cognitive restricting & $\begin{array}{l}\text { In cognitive restricting, beliefs, } \\
\text { interpretations, individual self- } \\
\text { talk and distorted cognitive } \\
\text { processes were intervened. } \\
\text { Therapist was about to identify } \\
\text { ineffective cognitive distortions } \\
\text { and teach the logical and } \\
\text { organized thinking methods to } \\
\text { family in this session }\end{array}$ \\
\hline Eighth session & Training of positive thinking & $\begin{array}{l}\text { It was taught to family members } \\
\text { to think positively in this session }\end{array}$ \\
\hline Ninth session & $\begin{array}{l}\text { Training of communicational } \\
\text { skills improvement }\end{array}$ & $\begin{array}{l}\text { In this session, therapist taught } \\
\text { communicational skills to family } \\
\text { members emphasizing on two } \\
\text { principles of } 1 \text { - skill of effective } \\
\text { expression 2- skill of being an } \\
\text { active listener. The second part }\end{array}$ \\
\hline
\end{tabular}




\begin{tabular}{|c|c|l|}
\hline & & $\begin{array}{l}\text { of this session was related to } \\
\text { sympathy skill. In sympathy } \\
\text { training, person emotionally } \\
\text { responded through percept of the } \\
\text { reactions of others }\end{array}$ \\
\hline Tenth session & Training of anger-control skill & $\begin{array}{l}\text { In this session, therapist taught } \\
\text { cognitive behavioral principles } \\
\text { of anger control }\end{array}$ \\
\hline Eleventh session & $\begin{array}{l}\text { In this session, therapist had a } \\
\text { question and answer meeting } \\
\text { with family members. The } \\
\text { opinions of family about the } \\
\text { conducted interventions was } \\
\text { asked and then the results was } \\
\text { assessed and pluralized and } \\
\text { family was planned }\end{array}$ \\
\hline Twelfth session & Conclusion & $\begin{array}{l}\text { Questionnaires were again } \\
\text { implemented and participants } \\
\text { were post tested }\end{array}$ \\
\hline & Posttest implementation \\
\hline
\end{tabular}

\section{FINDINGS}

According to table 1, the scores of posttest in test group have been considerable decreased compared to pretest while there have not been any significant difference between scores of control group before and after implementation of cognitive behavioral protocol.

Table 1. Mean and standard deviation of gained scores within marital burnout questionnaire in pretest and posttest

\begin{tabular}{|c|c|c|c|c|}
\hline Group & \multicolumn{2}{|c|}{ Pretest } & \multicolumn{2}{c|}{ Posttest } \\
\hline & Mean & Standard deviation & Mean & Standard deviation \\
\hline Test group & $112 / 82$ & $14 / 35$ & $81 / 75$ & $12 / 42$ \\
\hline Control group & $102 / 34$ & $19 / 15$ & $100 / 20$ & $18 / 90$ \\
\hline
\end{tabular}

According to table 2, there is a significant difference between scores of pretest and posttest of test group while there is not any considerable difference between these scores of control group.

Table 2. Mean and standard deviation of gained scores within marital conflict questionnaire in pretest and posttest

\begin{tabular}{|c|c|c|c|c|}
\hline Group & \multicolumn{2}{|c|}{ Pretest } & \multicolumn{2}{c|}{ Posttest } \\
\hline & Mean & Standard deviation & Mean & Standard deviation \\
\hline Test group & $30 / 23$ & $6 / 98$ & $22 / 45$ & $4 / 33$ \\
\hline Control group & $30 / 45$ & $7 / 11$ & $29 / 78$ & $7 / 01$ \\
\hline
\end{tabular}

Table 3. Results of covariance analysis (ANOVA) of posttest scores of marital burnout

\begin{tabular}{|c|c|c|c|c|c|}
\hline $\begin{array}{c}\text { Changing } \\
\text { sources }\end{array}$ & $\begin{array}{c}\text { Sum of } \\
\text { squares }\end{array}$ & Mean squares & F & Effect size & Sig level \\
\hline $\begin{array}{c}\text { Effect of } \\
\text { pretest }\end{array}$ & $32 / 54$ & $32 / 54$ & $18 / 09$ & $0 / 65$ & $0 / 001$ \\
\hline Effect of group & $1750 / 58$ & $1750 / 58$ & & & \\
\hline Error & $6215 / 94$ & $295 / 99$ & & & \\
\hline
\end{tabular}

Table 4. Results of covariance analysis (ANOVA) of posttest scores of marital conflict

\begin{tabular}{|c|c|c|c|c|c|}
\hline Changing & Sum of & Mean squares & F & Effect size & Sig level \\
\hline
\end{tabular}




\begin{tabular}{|c|c|c|c|c|c|}
\hline sources & squares & & & & \\
\hline $\begin{array}{c}\text { Effect of } \\
\text { pretest }\end{array}$ & $150 / 20$ & $150 / 20$ & $18 / 75$ & $0 / 46$ & $0 / 001$ \\
\hline Effect of group & $1692 / 75$ & $1692 / 75$ & & & \\
\hline Error & & & & & \\
\hline
\end{tabular}

\section{DISCUSSION AND CONCLUSION}

This study has been conducted to assess the effect of cognitive behavioral therapy on reduction of marital conflict and burnout. The obtained results of study indicated that training of cognitive behavioral skills could significantly effect on reduction of marital conflict and burnout and this result is coordinated with results obtained from studies of Arieta (2008), Chang (2003), Stiths (2004) and Shafeenia and Hosseinian (2007). According to theoretical bases of this study, from the perspective of Seamus the reason for the effect of cognitive behavioral family therapy is that many of cognitive behavioral solutions are applied in this field emphasizing on following options:

1- $\quad$ Determining of family members expectations from each other and their effects on interactions between family members

2- $\quad$ Benefiting from methods leading to increase in abilities of family members to deal with unexpected events, changes and crises (Seamus, 2002)

The main reason for the positive effect of cognitive behavioral family therapy on variables of study might have been related to this matter that problems of studies families have been interpersonal not intrapersonal. In other words, a small problem has led to conflicts between family members and this conflict has been increased during years. Therefore, one of the reasons for effect of cognitive behavioral family therapy could have been related to this matter that these interventions have led to correction of unreasonable and illogical, correction of negative communicational methods between family members and correction of unreal thoughts. Therefore, it can be stated that family therapy through cognitive behavioral method have helped families to properly face problems with settlement of conflicts between family members through training of techniques such as problem solving skills, interpersonal coping skills, stress coping skills, assertiveness skills, training of cognitive restructuring techniques, positive thinking, communication skills and sympathy for family.

\section{REFERENCES}

Pines, A. (1996). What should we preventing our love from burnout, Shadab Trans, (2002), Tehran, Ghoghnoos Pub

Mahmoudi, J., Sanaee, M., Nazari, B., Davarniya, A. M., Bakhtiari, S., Bahra and Shakarami, M., (2015). Efficacy of Short-term solution-based treatment on reduction of marital burnout and improvement of the quality of life of married women, Armaghn Danesh 2 (5)

Dattilio, F., Cognitive-behavioral therapy for couples and families, Nabiollah Khaje, Parinaz Sajadian \& Fatemeh Bahrami Trans, (2014), Isfahan, ARJMAND Pub

Davarniya, R., Zahrakar, K., Moayeri, N., Shahkarami, M., (2015), Assessment of efficacy of emotional-based couple therapy through group method and its effect on reduction of marital burnout among women, Islamic Azad University Journal of Medical Sciences, 25 (2), Pp. 32-140

Rostami, M., (2014, the effect of the approach of emotional-based couple therapy on improvement and increase in marital satisfaction, Behavioral and Social Sciences, 114, Pp. 52-

41

Shafieenia, A., Hosseinian, S., (2007), evaluation of the effectiveness of cognitive-behavioral group counseling method on marital conflicts, Psychological and Educational Research, 2 (2), Pp. -22

Alimoradi, L., Zaeemi, A., (2011), assessment of Pathology and reasons for divorce, Welfare Organization, Research Design, Pp. 31-56

Gladding, S., (2000), family therapy, history, theory and application, Farshad Bahari, Badri Sadat Bahrami, Soosan Seif, Mostafa Tabrizi Trans (2007), second edition, Tehran, TAZKIYE Pub

Arieta, M. T. (2008). Women s'couple relationship satisfaction, The impact of family structure and interparental conflict. Unpublished Doctoral Dissertation.Sanfrancisco University. 
Bastani, S., Golzari, B. \&Rowshani, SH. (2011).Emotional divorce and strategies to face it.Journal of family Resaerch, 7(2), 241-257.

Baucom, D.H, \& et al, 2010, Cognitive- behavioral couple therapy.In K.S. Dobson, Handbook of cognitive behavioral therapies, 3rdEd. New York: The Guilford press, p. 411-444.

Chang, S. L. (2008). Family background and marital satisfaction of newlyweds.Generational transmission of relationship interaction patterns.unpublished Master's Thesis, California State University

Dattilio, F. M, 2010, Cognitive-behavioral therapy with couples and families: Acomprehensive guide for clinicians, United States of America: The Guilford Press

Denton WH, Wittenborn AK, Golden RN.Augmenting antidepressant medication treatment of depressed women with emotionally focused therapy for couples: a randomized pilot study, J Marital FamTher 2012; 38: 23-38

Durden E. D. (2006). Marital Status, Marital Status Transitions, and Depression: Does Age Matter? Dissertation for the Degree of Doctor of Philosophy The University of Texas at Austin.

Elinaman,T. (2004). Resolving conflict in marriage. Family life, communications in corporated. Retrived form: www. findarticle.com

Huston T. what is love got to do with it? why some marriage succeed and other fail. Journal of Personal Relationship 2009; 16: 301-27.

Johnson, H. A. ( 2005). The Contribution of Couple Leisure Involvement. Leisure Time, and Leisure Satisfaction to Marital Satisfaction.Tesis for the degree of Master of Art. Brigham Young University, Department of Recreation Management and Youth Leadership.

Kayser K. The marital disaffection scale: An inventory for assessing motional estrangement in marriage, Am J FamTher 1996; 24(1): 68-80

Laes,T. Laes,T. (2001). Career burnout and its relationship coupleburnout in Finland. Annual meeting of the American psychologicalassociation 109,24-28

Pines AM, Neal MB, Hammer LB, Icekson T. Job burnout and couple burnout in dual- earner couples in the sandwiched generation. Social Psychology Quarterly 2011; 74: 361-86.

Pines, A.M., Nunes,R. (2003). The relationship between career andcouple burnout: implication for career and couple counseling.Journal of employment counseling 40(2), 50-64

Stein, D., Harvey, B., Uys, J., \& Daniels, W. (2005), suffer the children: The psychobiology of early adversity. CNS Spectrums: The International Journal of NeuropsychiatricMedicine, 19, 612-615.

Stiths, S. M. (2004). Treating intimate partner violence with in intact couple relationship: Outcomes of multi-couple versus individual couple therapy. Journal of Marital and Family Therapy. 14. 499-520

Young, J. E, \& et al, 2003, Schema therapy: A practitioner'sguide. New York: Guilford Press.

Zarei E, Sadeghifard M, Adli M, TayebiSoogh M. The Effectiveness of Ellis couple therapy training (The rational-emotional-behavioral approach) on reducing the marital burnout. Journal of Life Science and Biomedicine 2013; 3: 229-32. 